\title{
Analysis of Advantages and Disadvantages of Computer-assisted Instruction in English Teaching
}

\author{
Zhang Ya-nan \\ School of Foreign Languages, Nanyang Institute of Technology \\ Nanyang, China, 473004 \\ knightv97@sohu.com
}

\begin{abstract}
With the development of science and technology, especially since the application of computer technology, computer aided instruction (CAI) has also entered the thousands on thousands of classroom. Now the computer assisted instruction (CAI) has become an advanced teaching means of quality education in teaching. CAI for the convenience and efficiency of English classroom teaching at the same time, its disadvantages inevitably highlights. This paper discusses the advantages and disadvantages of CAI, which is expected to play a good role in the educational and teaching activities.
\end{abstract}

Keywords-English teaching; computer-assisted; CAI advantages and disadvantages

\section{INTRODUCTION}

Traditional English teaching model is primarily based on teachers' lecture, which takes textbooks as the main information resources. In such mode, teaching method is relatively single and teaching process is relatively mechanical; too much emphasis are taken on imparting language knowledge, while ignoring the language skills training, thereby reducing the efficiency of teaching. Based on multimedia educational technology, computer-aided English teaching is changing the traditional classroom teaching mode. It not only brought a new breath to the college English teaching, but also brought new challenges to teachers.

Computer Assisted Instruction (Computer Assistant Instruction, referred CAI) is a set of voice, text, graphics, animation, video and other computer technology in one of the modern teaching methods. CAI its image clear, strong sense of dynamic, informative, interactive and flexible advantage, to help improve the efficiency of classroom teaching, thus emphasizing the teaching points, breaking the difficulty of teaching, play a multiplier effect [1]. Computeraided teaching methods in English teaching practice, making traditional English teaching mode change, new language learning environment for students.

\section{THE THEORETICAL BASIS}

\section{A. Behaviorism}

"Behaviorists believe that learning is one kind of correspondence between the stimulus and response. The Basic assumptions are: the behavior is the learner's response to environmental stimulation," [2]. As a stimulus the environment accompanied and followed the organism acts as a reaction to that all behavior is learned. Application of behavioral learning theory in the practice of school education is to urge teachers to master the method of shaping and correct student behavior, creating a learning environment for students, as much as possible to strengthen the students to the maximum extent appropriate behavior and eliminate inappropriate behavior.

\section{B. Constructivism}

Constructivism origins can be traced back to Italian philosopher Vico 300 years ago, after the 20th century, fueled by Dewey, Piaget, Vygotsky, Oswald Bell, Bruner etc, with the gradual improvement and maturity of constructivism, such a philosophical concepts begin to be applied to the fields of study. "Constructivism learning concept believes: Learning is a process of acquiring knowledge; the knowledge is not given directly by external stimulus, but the result of the interaction of external stimulus and internal mental process of knowing subject. Knowledge is not obtained from teachers' teaching, but with the help of others, based on social and cultural context, learners acquire it by the way of the construction of meaning in some certain scenarios. [3]”, Constructivist learning methods advocated under the guidance of a teacher, a learner-centered learning that is to emphasize the main role of the learner's cognitive, without losing sight of the guiding role of teachers, teachers' role are constructive assistant and facilitator rather than imparting knowledge and instilling those. Students are the main body of the construction of meaning and significance active constructors, rather than passive recipients of external stimuli and indoctrination object. Constructivism considers, "scene", "collaboration", "session" and "meaning construction" are the four elements in the learning environment. The learning environment must be conducive to the meaning construction of what students have learned in the content, and collaboration throughout the whole process of learning activities, the exchange is a the basic collaborative process or a connection, and meaning construction is the ultimate goal of the teaching process. 


\section{THE ADVANTAGES OF CAI ENGLISH TEACHING}

\section{A. CAI Optimize the Structure of Classroom Teaching}

As a new teaching methods CAI teaching technology tend to be all-round, multi-level, and it can make the teaching contents vivid, interesting and fascinating. Transformed from teachers explaining tool to students' cognitive tool, the CAI courseware changes the function of instructional media. Constructivism emphasizes the use of a variety of information resources to support "learning" rather than support "teaching". By the way of developing the perfect resource repository, teachers could guide the students' self-learning or collaborative learning. Specific implementation process of foreign language teaching is set in the classroom; which is the main place for the communication of teacher and student. In the process of teaching in the classroom, it is appropriate to use the projector, audio, video and other media, teacher can make the teaching process more vivid, intuitive, and such way could promote the overall optimization of teaching effectiveness. CAI can achieve a variety of information in text; image and sound synchronization output, with a strong two-way interactive dynamic simulation function and manmachine dialogue advantage, the teaching contents are combined to a perfect whole. Such an effect of teaching activity traditional teaching media can not be achieved.

\section{B. CAI is Convenient for Interactive Operation}

These CAI features greatly enhance the degree of student participation in learning, and stimulate students' interest in language learning. Constructivist learning theory emphasizes students actively involved is the key factor to improve learning outcomes. By the way of providing students with a variety of teaching resources and the creation of a learning situation, CAI courseware would enable students to participate in the teaching activities as learning subjects, and knowledge can be achieved through the construction of meaning. On one hand, the bright colors, cute cartoon characters, magical animation on the screen effectively attract the students' attention; students' involuntary attention could be aroused. On the other hand, by operating the computer to complete the learning task, the students' curiosity and sense of accomplishment has been greatly fulfilled.

Melodious sound and background music could create a very relaxed learning atmosphere, and students would naturally be immersed in the enjoyment of learning. Teaching students in this way can achieve excellent results, their reading, reciting and speaking ability have been constantly enhanced, and their interest in learning have been greatly stimulated. By the way of improving the enthusiasm of students and applying multimedia teaching in classroom teaching, not only the interaction between the students and the machine can be achieved, but also multi-directional communication between students and students, between students and teachers can be reached [4].

\section{Computer Network Realize Sharing of Oline Teaching Resource}

Reserving and sharing of information resources, multiple information channels are to help improving information memorizing effect. CAI obtains more obvious advantages in feedback regulation and learning exchanges, compared to other audio-visual means. Traditional lecture teaching content is difficult to store in large-capacity and long-term preservation. The successful multimedia courseware is main wealth in teaching. It is an important way of learning exchange among teachers. Through the fasttrack of the Internet, teachers can download excellent courseware processed by computer. Teachers can share their teaching experience be the way of campus network. By such method teachers can make jointly improvements their teaching, and truly shared teaching resources can be achieved and better teaching service can be provided.

In addition, with a vast of English online resources would enable CAI to prompt the teaching efficiency of English reading. Reading is a very important link in the teaching of English. For the reason of its rich in resources online reading, can greatly enrich and develop students' reading ability. Through students mutual consultations in the reading process and publish of their online reading experience, the students online session exchanges have unlimited space.

\section{Disadvantages Of CAI IN ENGLISH TEACHING}

Although it promote classroom teaching in large degree, and improve classroom teaching efficiency, CAI, after all, exist as a means of teaching, its role is inseparable to teaching ideas and teaching theories. Although in its developing process CAI continues to improve, there are still some undesirable places as the following:

\section{A. In the Teaching Process CAI always Taken as a Stimulus Tool}

The theoretical basis of the traditional teaching is behavioral learning theory its typical model is stimulusresponse. In a certain period CAI production theory influenced by Behaviorism, too much emphasis are laid on the visual, auditory stimulation, and focus only on the advantage in auditory and visual stimulus, and increase the intensity of stimulation. Although some results have been achieved in improving student learning efficiency, such teaching courses are just taken the computer as a tool of stimulus.

In teachers' application of CAI in their teaching, often appear overly dependent on the software platform, which will inevitably reduce the direct interaction between students. From different aspects of view of human development, multimedia characteristics or the basic regulations of teaching and learning, multimedia as a new kind of teaching and learning means, it must be restricted to maximize the effectiveness under certain conditions; unconditional use may produce disastrous teaching effects. 
However, in the actual teaching activities, there are some improper situations in applying CAI. Such as: for the media and to the media, the generic media and so on.

\section{B. CAI Teaching Emphasize too much as assistant}

According to constructivist theory, in the process of implementation of teaching activities, students should be seen as the main body of learning activities, and teachers just play the role of guidance to assist students. Through students' own cultural background, the acquisition of knowledge can be realized through meaning construction. Such a theory emphasizes the students' main role in language learning.

Under the influence of the traditional teaching theory, the direction of CAI design is basically expand around how to "teach", less involved students how to "study" [5] . For this reason students are passive in using CAI. Using such a direction to design classroom teaching, the students may not have a lot of opportunities to participate in the teaching activities. Most of the time students are set in the status of passive acceptance, students' initiative and enthusiasm can not be stimulated. The implementation of quality education could be hardly conducted.

\section{CAI courseware lacks specificity on students' existing learning difficulties}

College students have different kinds of difficulties in their language learning, such as pronunciation, vocabulary, grammar, short-term memory, attention and mood etc. The teaching material of college teaching English is default, and the courseware is the default, or even answer the answer to the problem of students is somewhat default. Those defaults are only based on the experience and feeling that it can not solve some specific problems in student language learning.

\section{Teachers' Abilities on Computer Application and Understanding of CAI need to be improved}

Teachers' consciousness of using CAI is still relatively poor, and some teachers' abilities on computer application are not high, which makes it difficult to use of multimedia in their teaching activities. To make the CAI really go deep into the teaching to achieve the integration of CAI and English course, the key is to improve teachers' understanding of the CAI and computer application ability. Thus realization of true constructivism can be achieved by emphasizing the supporting role of teachers as well as the CAI teaching supporting role.

\section{NEW REQUIREMENTS ARE MADE TOWARDS ENGLISH TEACHERS FOR THE REASON OF CAI}

CAI requires teachers to be multi-skillful, not only can they compile the multimedia courseware and to replenish new teaching content according to their own teaching needs, but also can help solve some of the problems encountered in operating computer. The teachers are supposed to master computer technology, and to apply it in teaching. It is improper to operate computer by themselves or urge students a wholly independent autonomous learning. Teachers should be the organizer of the classroom teaching, there should be more emphasis on "integrated model"(technology integrated in the curriculum and teaching, emphasizing the combination of technology and the overall teaching, focusing on the technological teaching, rather than technical itself.) The entire teaching process, teachers need to explain not only key vocabulary and cultural background knowledge, but also explain listening strategies, language skills ant speaking requirements. Through the feedback information, teachers should adjust teaching procedure timely; determine the appropriateness of teaching content; find the reasons of students' poor performance and suggest improvements to the students in a timely manner [6].

Teachers' teaching attitude, teaching concepts, teaching interests, motivation levels and emotional state will affect the students' enthusiasm for learning. Therefore, teachers should adopt a positive attitude to infect students, to encourage students to various forms in their teaching. Appreciate, praise, encourage and guide will enable students in a relaxed state of mind, and it will trigger the initiative and enthusiasm of the students; enhance students' selfconfidence; and improve teaching effectiveness.

\section{SUMMARY}

With the deepening reform on English teaching, CAI is bound to be involved the whole process of English teaching. A good CAI courseware is a perfect integration of content and form, it can improve the efficiency of classroom teaching, and please students to stimulate their interest, and furthermore better teaching results can be achieved. So how to play computer advantages of multimedia technology in English teaching, meanwhile overcome CAI's inadequacies and weaknesses is very important. The extensive application of CAI will eventually update the consciousness and concept of the English teachers in using of modern technology. And finally the application of CAI may promote the change of traditional teaching mode, and thus further the process of English teaching reform.

\section{REFERENCES}

[1] L. Zhiguo, "My View on Multi-media Teaching”. Anhui Business Vocational and Technical College, 2002, (3): pp60-61.

[2] B. Yufang, “Educational Psychology”, Hangzhou: Zhejiang Education Publishing House, 2009, p98.

[3] C. Qi , L. Rude, “Contemporary Educational Psychology”, Beijing : Beijing Normal University Press, 2007:pp16-18.

[4] S. Li, "CAI and English Teaching", the Journal Heilongjiang Education College, 1998, (2):pp69 -70.

[5] X. Minggao, "Based Constructivism: Multimedia Teaching Problems and Countermeasures", Scientific and technological information, 2009, (35):p986.

[6] Yi. Weimin, "The basis of modern educational technology applications" Anhui Education Press, 1999:p206 
